\title{
Introduction to the special issue on cognitive consequences of bilingualism
}

\author{
Ramesh Mishra $\cdot$ Jubin Abutalebi
}

Published online: 19 October 2020

(C) Springer Nature Singapore Pte Ltd. 2020

The relationship between bilingualism and general cognitive abilities has recently attracted considerable attention. A central idea in this regard is that bilinguals' cognitive abilities may be boosted as a consequence of that they have to deal with two (or more) languages most of the time. 'Managing' two or more languages, for instance, may require some explicit or implicit inhibition of the context inappropriate language. The exact mechanisms of such cognitive and neural processing in bilinguals and its general consequences are hotly debated. One reason for this appears to be political. In some countries, such as the United States, the notion that bilingualism has detrimental effects on child development had been widespread. As a reaction to this widely held false belief, many language researchers in North America set out to collect experimental evidence to investigate the issue experimentally and correct such claims. Interestingly, this body of research obtained many results that suggested that bilingualism bestows enhanced abilities on the bilingual (especially with regard to cognitive control, e.g. Bialystok and Craik 2010; Emmorey et al. (2008) rather than

R. Mishra $(\bowtie)$

Hyderabad, India

e-mail: rkmishra@uohyd.ac.in

J. Abutalebi

Milan, Italy detrimental effects as had previously been thought. This brings us to the second controversy, namely, that many of the cognitive advantages could not be replicated (e.g. von Bastian et al. 2016) and were subsequently re-evaluated as reflecting false positives or publication bias by some researchers (e.g., De Bruin et al. 2015; Nichols et al. 2020). We will not attempt to take a stance either way in this editorial. Two things however are important to realise. First, researchers on both sides agree that learning a second language (or more) is good for people simply because it allows bilinguals and multilinguals to engage (and often) embrace another language community and culture. The old idea that learning another language is bad for you is no longer shared by any serious researcher. Second, the whole controversy is very much a result of WEIRD (Western, Educated, Industrialised, Rich, Democratic, cf. Muthukrishna et al. 2020) psychology. In countries such as India, almost everybody (i.e. almost one billion people) speaks multiple languages, the notion that multilingualism may be bad for you, had indeed been considered more than a little weird.

This was the background when in November 2018 Ramesh Mishra (University of Hyderabad, Hyderabad) and Veeky Baths (BITS Pilani Goa Campus, Goa) invited leading bilingualism researchers from across the world to take part in a workshop on the issue of cognitive consequences of bilingualism. This special issue is a result of the fruitful discussions that happened at this workshop. One of the most inspiring 
contributions at the workshop were made by the late Albert Costa. Albert Costa was a prolific and hugely influential scholar not only in bilingualism but also in many other fields in cognitive science. Costa's seminal contributions on the topic of bilingualism are especially highly regarded. The Goa workshop turned out to be Albert's last conference. This special issue is dedicated to his memory.

The articles in this issue address a range of issues in the broad area of bilingualism. Many papers directly focus on the issue of cognitive advantages of bilingualism. Gallo et al. (2020) review literature on cognitive reserve that occurs over time as a result of a lifelong bilingualism. They make a conceptual difference between cognitive and brain reserve. They argue that lifelong practice of bilingualism can boost both the structural and functional properties of brain networks thereby enhancing cognitive functioning in old age. Chen et al. (2020) examined performance in Chinese-English bilinguals on a translation production task. They collected both linguistic as well as cognitive control data. The study shows that translation in bilinguals is affected by both linguistic and non-linguistic variables. Del Maschio et al. (2020) provide some evidence and arguments that second language use rather than knowledge is the key determinant of changes in white matter structure. Grundy et al. (2020) conducted a quantitative analysis on the effects of bilingualism on executive functions to argue that bilinguals perform better than monolinguals on executive function tasks even when confounding factors are taken into account. Bhandari et al. (2020) present evidence that bilinguals, particularly those who are high proficient in their second language, bring in higher executive control when the context becomes demanding. Thanissery et al. (2020) similarly find that high proficient bilinguals perform better on inhibitory control tasks replicating many previous findings of Singh and Mishra (2012, 2013) on Hindi English bilinguals using behavioural tasks. Arora and Klein (2020) conducted a meta-analysis comparing monolinguals and bilinguals on the attention network task (ANT), a task which Albert Costa had used in his pioneering work. They specifically focus in the different attention networks that this task taps into i.e. alerting, orienting and executive control. They conclude that while there may not be much difference between bilinguals and monolinguals in the alerting and orienting tasks, there is a difference in young adults on the executive control component of the task. Bodig et al. (2020) investigated the foreign language effect and decision-making in bilinguals. They particularly focus on the optimality bias. The study shows that bilingualism modulates how bilinguals ascribe blame in their different languages. Finally, Rodrigo et al. (2020) examine the issue of word order flexibility and control in bilinguals. They argue that their finding suggests that structural selection and word order choice are independent processes in languages with great flexibility in word order choice.

We thank Vaishnavi Mohite who lent great assistance in the coordination of the special issue.

Ramesh K. Mishra and Jubin Abutalebi.

Guest editors

\section{References}

Arora, S., \& Klein, R. (2020). Comparing bilingual and monolingual performance on the Attention Network Test: Metaanalysis of a literature inspired by Albert Costa. Journal of Cultural Cognitive Science. https://doi.org/10.1007/ s41809-020-00068-z.

Bhandari, P., Prasad, S., \& Mishra, R. K. (2020). High proficient bilinguals bring in higher executive control when encountering diverse interlocutors. Journal of Cultural Cognitive Science. https://doi.org/10.1007/s41809-02000060-7.

Bialystok, E., \& Craik, F. I. (2010). Cognitive and linguistic processing in the bilingual mind. Current Directions in Psychological Science, 19(1), 19-23.

Bodig, E., Toivo, W., \& Scheepers, C. (2020). Investigating the foreign language effect as a mitigating influence on the 'optimality bias' in moral judgments. Journal of Cultural Cognitive Science. https://doi.org/10.1007/s41809-01900050-4.

Chen, P., Hayakawa, S., \& Marian, V. (2020). Cognitive and linguistic predictors of bilingual single-word translation. Journal of Cultural Cognitive Science. https://doi.org/10. 1007/s41809-020-00061-6.

De Bruin, A., Treccani, B., \& Della Sala, S. (2015). Cognitive advantage in bilingualism: An example of publication bias? Psychological Science, 26(1), 99-107.

Del Maschio, N., Sulpizio, S., Toti, M., et al. (2020). Second language use rather than second language knowledge relates to changes in white matter microstructure. Journal of Cultural Cognitive Science. https://doi.org/10.1007/ s41809-019-00039-z.

Emmorey, K., Luk, G., Pyers, J. E., \& Bialystok, E. (2008). The source of enhanced cognitive control in bilinguals: Evidence from bimodal bilinguals. Psychological Science, 19(12), 1201-1206.

Gallo, F., Myachykov, A., Shtyrov, Y., et al. (2020). Cognitive and brain reserve in bilinguals: field overview and 
explanatory mechanisms. Journal of Cultural Cognitive Science. https://doi.org/10.1007/s41809-020-00058-1.

Grundy, J. G. (2020). The effects of bilingualism on executive functions: an updated quantitative analysis. J Cult Cogn Sci. https://doi.org/10.1007/s41809-020-00062-5.

Muthukrishna, M., Bell, A. V., Henrich, J., Curtin, C. M., Gedranovich, A., McInerney, J., et al. (2020). Beyond western, educated, industrial, rich, and democratic (WEIRD) psychology: measuring and mapping scales of cultural and psychological distance. Psychological Science, 0956797620916782 ,

Nichols, E. S., Wild, C. J., Stojanoski, B., Battista, M. E., \& Owen, A. M. (2020). Bilingualism affords no general cognitive advantages: A population study of executive function in 11,000 People. Psychological Science, 31(5), 548-567.

Rodrigo, L., Tanaka, M., \& Koizumi, M. (2020). The role of word order in bilingual speakers' representation of their two languages: the case of Spanish-Kaqchikel bilinguals. Journal of Cultural Cognitive Science. https://doi.org/10. 1007/s41809-019-00034-4.
Singh, N., \& Mishra, R. K. (2012). Does language proficiency modulate oculomotor control? Evidence from Hindi-English bilinguals. Bilingualism: Language and Cognition, 15(4), 771-781.

Singh, N., \& Mishra, R. K. (2013). Second language proficiency modulates conflict-monitoring in an oculomotor Stroop task: evidence from Hindi-English bilinguals. Frontiers in psychology, 4

Thanissery, N., Parihar, P., \& Kar, B. R. (2020). Language proficiency, sociolinguistic factors and inhibitory control among bilinguals. Journal of Cultural Cognitive Science. https://doi.org/10.1007/s41809-020-00065-2.

Von Bastian, C. C., Souza, A. S., \& Gade, M. (2016). No evidence for bilingual cognitive advantages: A test of four hypotheses. Journal of Experimental Psychology: General, 145(2), 246.

Publisher's Note Springer Nature remains neutral with regard to jurisdictional claims in published maps and institutional affiliations. 